\title{
Application of Motivation Theories in the Construction Industry
}

\author{
Omotayo Olugbenga Aina \\ Department of Building, Obafemi Awolowo University, Ile-Ife.
}

\begin{abstract}
This study examined the suitability of the motivation techniques used in the construction industry and their underlying theories. These techniques and theories were adapted from psychology and management literature/practice. Though this adaptation was necessary, yet, it queries the basic principle of motivation, which stipulates that motivation depends on the environment, the man and the job characteristics. These all differ in the construction industry when compared with manufacturing and purely management settings.

Historically, application of motivation techniques in the construction industry is rooted in the basic Maslow, Herzberg and McGregor's theories underlying such practices in the service and manufacturing industries. Analysis of field application of these theories revealed that certain peculiarities of the construction industry have influenced them. For example, union influence limit options of the theories that can be adopted in the construction industry, a clear boundary between factors in the Herzberg's theory does not exist when applied to workers in the construction industry, and Maslow's theory is also not empirically supported by the behaviour of some construction workers. And mixtures of the rigidly categorized $X$ and $Y$ classes of the McGregor's theory are the norm in the construction industry.

The study concluded that, though the foundational motivation theories are desirable, but collation and summary of empirical based flaws in their application in the construction industry is necessary and that a further test of the effects of the peculiarities of the construction industry on the effectiveness of these theories which have been effective elsewhere is equally desirable.
\end{abstract}

\section{Introduction}

Productivity improvement in the construction sector, being a largely unautomated industry unlike its manufacturing counterpart, is dependent largely on the contribution of the human component of construction resources. While the use and management of capital equipment in construction operations may be complex, it tends to be fairly consistent and predictable. Humans on the other hand do not behave in a regimented or mechanistic manner, and therefore create a number of difficulties that are not apparent in the management of plants. Though characterised by lesser predictability, human as the main coordinating resource on construction sites, must have its peculiarities, fully understood by construction practitioners, in order to stimulate and fully harness its potential.

Past empirical studies showed that application of motivation techniques basically developed by psychologists and applied in pure management organisations have also been used to improve productivity in the construction industry. Shrader (1972), Borcherding (1981) and Aina (2000). While this is commendable, other research efforts in the industry have however noticed some lapses in the application of these techniques and their underlying theories in the construction industry. (Yap, 1992. Haseltine 1976). These lapses reduce the motivating strength of these techniques and theories.

Therefore, the premise for this research is that these motivation techniques were not basically designed for workers in the construction industry thus resulting in the need to assess whether they are completely suitable for the industry.

\section{Concepts of job motivation}

The concept of motivation has taken many forms, behavioural scientists believe it to be a motive based concepts, which in turn is based on needs, which are consciously or unconsciously felt. Berelson and Steiner (1964) Defined the term "motive" as an inner state that energizes, activates or moves and directs individuals to channel behaviour towards goals. In other words, motivation is a general term applying to the entire class of drives, desires, needs, wishes and similar forces.

Eze (1995) described motivation as a psychological process initiated by existence of a need and involving a goal, a purposive activity directed towards reaching a goal and thereby satisfying the needs. The process can be understood in its simplest form as a three step process: first there is an internal need; second a behavioural action or direction to satisfy that need and third, the accomplishment or the satisfaction of the need. It may therefore be viewed as a set of individual relationships that explains the direction, and persistence of an individual behaviour.

However, in the views of Berelson and Steiner (1964); Novarcek and Lazarus (1990) motivation is not 
only the inner state that activates, but also disposition which reacts to the demands, constraints and resources presented by the environment Elsewhere, Dunnette (1973) sees motivation as a label for: The choice to initiate effort and the choice to persist in expending effort over a period of time to achieve a given performance objective. In the views of Steers and Porters (1983). Three major components of motivation can be identified; the first is an energizing component which is the force or drive present in an organisation which leads to some behaviour. Second, there are some directing functions that guide the behaviour once it has occurred, this third component is particularly important to work settings, employees once hired and placed on jobs are expected to maintain good performance as long as they remain in the organisation. Presently, there is substantial amount of literature on job motivation in general business and management world. The basis of research into construction operatives motivation is the general understanding of motivation as being dependent on the environment, the personality involved and the task or job characteristics. Since the construction industry offers a different working environment and distinct job characteristics from other industries, job seekers should be repeatedly studied so as to acquire specific knowledge on their motivation needs.

\section{Types of motivation}

Though individuals have different needs that vary considerably. Halloran showed that there are essentially three types of motivation that affect all classes of people, namely; fear, incentive and attitude. Fear motivation causes individuals to react in a certain way because they are afraid of the consequence of the contrary. Humans were introduced to fear motivation very early in life, because if parents were disobeyed the erring child was spanked. The fear of possible results of more disobedience motivate the child to suppress such future desires for disobedience.

There are many forms of fear motivation in the society, the laws of the land impose fear through arrests and penalties if certain stipulations were disobeyed. This form of motivations is termed "Kick in the Ass" (KITA). Incentive motivation is through the use of a tangible or intangible reward for an action. Adults work for incentive in form of the four Ps of motivation, namely: praise, prestige, promotion and paycheques, it may be in the form of accolades, social acceptance and commission, this is also termed as the "Carrot Approach". The incentive motivation is the pull mechanism while the fear motivation is the push mechanism. The philosophy of attitude or self motivation is based in the understanding of human nature. Attitude motivation works on a personal set of goals not on a goal set by others.

\section{Motivation Theories}

Numerous theories have been proposed to explain the nature of motivation at work, but no generally acceptable theory has arisen (Langford 1995). The factors affecting motivation vary over time and according to circumstances, in addition, the subject draws on a wide range of diverse psychological and sociological bases. Langford et al (1995) have classified the theories under two headings, namely content and process theories, while Olomolaiye and Price (1990) called them conceptual and empirical theories.

\section{Content Theories}

Content theories are concerned with what is within an individual that generates behaviour. It examines the specific nature of the driving force in an individual. The prominent ones among these are those propounded by Herzberg (1959), Maslow (1943) and Magregor (1960).

\section{Herberg's Motivation/Hygiene Theory}

Herzberg (1959) reported a survey of 200 engineers and accountants who were asked to recall incident at work that increased or reduced their satisfaction and what effects these incidents had on their attitudes and performance. He concluded that these responses could be grouped under two headings: one hygiene factors, which are primarily concerned with job environment and which are extrinsic to the job itself. These affect dissatisfaction. Two motivator factors which are mainly concerned with the content of the work itself. The strength of these affect satisfaction, but not dissatisfaction. Thus, according to Herzberg, if a company fails to provide adequate hygiene factors, the workers are dissatisfied no matter how adequate the salaries and working conditions. Herzberg suggested that the workers would not be satisfied until all other motivators are satisfied.

\section{Maslow's hierarchy of needs}

Maslow considered that humans have five identifiable needs, namely physiological, safety, social, esteem and self-actualization and that these are ordered hierarchically according to whatever need is proponent. He believed that humans would not try to satisfy a need at the next level in the hierarchy until the lower level needs have been satisfied. Maslow's work has been influential and has had a significant impact on management approaches to motivation and design of organisation to meet employee needs. While appearing instinctively logical, this theory has been widely critised for lacking in empirical support. 


\section{Magregor's Theory $\mathrm{X}$ and Theory $\mathrm{Y}$}

Magregor (1960) believed that managers try to motivate people according to whether they hold a basically negative $(\mathrm{X})$ or positive $(\mathrm{Y})$ view of human beings. He further described Theory $\mathrm{X}$ as representing the traditional approach to the direction and control of people. He claimed that the approach rests on the following assumptions:

(a) That workers have an inherent dislike of work and will avoid work whenever possible.

(b) That since workers dislike work, they must be coerced, controlled, directed and punished to achieve organisational goals.

(c) That most workers prefer to be directed, wish to avoid responsibilities and have little ambition and desire security above all else.

(d) His theory $\mathrm{Y}$ offers an opposite view of people and is based on assumption that

a) Work is as natural as rest and play

b) Self direction and self control are desirable in the work situation

c) People are not inherently lazy, they become that way as a result of experience.

d) People have potential, under proper conditions, they learn to accept and seek responsibilities, they have imagination, ingenuity and creativity that can be applied to work.

McGregor believed in theory $\mathrm{Y}$ and felt managers holding these views were more likely to successfully motivate their work force than those that subscribed to theory X.

\section{Process Theories}

Process theories investigate how motivated behaviour is sustained. These more contemporary views are results of empirical studies. They tend to be objective, though human beings tend not to be particularly objective in their feelings and behaviour.

\section{Equity Theory}

This is concerned with the notion of fairness. The approach supposes that a major determinant of job satisfaction and performance of the individuals perception of the relationship between input and output. Input refers to the amount of work put in, while output is the reward from the work. According to Adams (1965) and Pritchard (1969) people calculate this relationship in terms of a ratio which they compare with their own calculation of the same as it relates to others who they consider to be comparable in job terms.

In cases where the two ratios are perceived to be the same, equity is said to exist, and where there is difference, inequity exists, and the person will consider himself as under or over rewarded. In cases of inequity, individuals are likely to find themselves in a state of tension and will be motivated to reduce it. Robbins (1991) suggests that individuals reduce or avoid tension by any of these alternatives, namely:

(a) Altering either own or other inputs and outcomes

(b) Attempting to influence the other person to change their inputs and outcomes,

(c) Redesigning the job and

(d) Distorting either their own inputs or outcomes.

On the other hand Landy and Thrumbs (1976) found that people perceiving themselves to be overpaid would take to any of the following alternatives.

(a) Reduce the quantity of production in piece rate, but increase the quality,

(b) Increase the quantity and the quality of production on time rate while those who consider themselves underpaid will attempt to reduce the tension by any of the following alternatives.

i) Increasing the quantity of production on piece rate, but decrease the quality

ii) Decrease the quantity and the quality of production on time rates.

Newcombe (1990) also considers that equity theory offers an important implication for managerial practice, particularly in designing jobs, rewards systems and promotion policies.

\section{Expectancy Theory}

This is derived from the early works of Lewin (1934), Vroom (1964) and Porter and Lawler (1968). It assumes that individuals make decisions and behave according to what they believe, the outcome of a particular action will be based on how attractive that action is to them. McCormic and Daniel (1985) call it a cognitive system, based upon a rational economic view of human nature, this could also be considered as being based on self interest, where individuals know what they want and assess the chance s of getting it and the means by which it can be attained. The core idea is that individual perceives certain links between effort, performance and outcome, these are: effort performance linkages, valency (attractiveness) of outcomes. Mascon et al (1985) 
pointed out, that if any of these links which are crucial to motivation are weak, the motivation and subsequent performance is like to be low.

\section{Goals Setting Theory}

This was developed by Locke (1968), it stresses the significance of setting and achieving of goals in the motivation process. The central idea is that an individuals conscious intention (goals) regulate his action. Locke opines that difficult goals lead to higher level of output, than easy goals. Furthermore, specific and difficult goals lead to a higher level of output than vague goals. The belief is that people who participate in setting goals will work harder to achieve them than people who are simply assigned goals. Hancock (1990) supports this idea and point out that we are all prepared to set tougher goals for ourselves than we will allow other to impose upon us.

Goal setting theory is conceptually aligned with management by objective (MBO), which though is a good idea, its implementation has experienced bottlenecks of heavy layer of bureaucracy.

\section{Influence of motivation theories in the construction industry.}

Need for higher productivity in the construction industry has led to her use of motivating techniques based on the basic motivation theories described above. The industry has used techniques based on the three broad streams of motivation, viz, KITA, carrot and stick and attitude, and those based on Herzberg's and Maslow's basic theories on motivation. There have also been research efforts on possible application of Magregor's theories and other later theories mentioned earlier. The industry has used financial motivators, semi financial motivators and non financial motivators.

Financial motivators, based on cash rewards are the closest connection between individual effort or performance and individual pay. Two main types are used, based on non rated output, the piece rate system and the standard hourly rate. The system determine an appropriate amount of work to be accomplished within a period of time and defines it as a standard, a fair rate is then set. The piece rate is then calculated by dividing the base wage by the standard. This basic piece rate provides a production incentive based on production beyond standard. This approach suffers from production variability, which disturbs the flow of production, variability occurs because employees may be willing to forgo extra effort and pay on some occasion of ill health and boredom. Its other major problem is that it promotes an adversarial relationship between workers and management; where workers make every effort to maximize their financial gain by attempting to manipulate the system of setting rates. Some of the financial motivators used in the industry are profit sharing, piece work plan, measured day work, standard hour system hour saved. Plus rate and geared schemes.

Semi financial motivators were developed to fill the gaps that exists between the companies and workers objectives that the financial motivators cannot fill. In order to establish mutual loyalty and commitment on both sides. There motivators also termed fringe herefits do not rely on cash motives, but concentrate an benefits such as holidays with pay, staff canteens, luncheon vouchers, sports facilities pension schemes, temporary bus, paid telephone bill and expense accounts. These help to satisfy Herzberg's hygiene factors and Maslow's higher needs.

Non financial motivators are fairly intangibles and are related to Maslow's higher needs and Herzbergs motivating needs. It acknowledges the importance of the individual, gives self fulfillment, self expression and recognize the need for group participation to provide social satisfaction. Examples of this in construction are the highly skilled craftsmen who obtain their fulfillment from the use of such skills and the public's acknowledgement of their expertise.

\section{Limitations of motivation theories in the construction industry}

Though it is agreeable that the motivation techniques used in the construction industry have their roots in basic theories (Maslow and Herzberg's). For example, the financial incentives used in the industry satisfy the Hygiene and physiological groups of Herzbergs and Maslow respectively, while the semi and non-financial incentives confirm the importance of Maslow's higher needs and Herzberg's hygiene needs. However, besides these identification with the roots, a wholesale adoption of these theories in the construction industry has not been made possible because of the industry's peculiarities. For example, in applying Herzberg's theory to Labour only subcontractors, Yap (1992) could not confirm the existence of such a clear boundary between motivating and hygiene factors as proposed by Herzberg. He believed that those definitive categories do not adequately represent feelings of those currently employed in the construction industry and the boundaries between them are much more vague than Herzberg proposed.

Elsewhere, Haseltine (1976) applied Herzberg's theory to construction operatives. He supports the view that the theory is a basic extention of Magregor's theories: that the traditional KITA (Kick in the Ass) oriented motivation techniques are not good motivator. Haseltine also believed that the domineering influence of construction unions in the United State of America offset most KITA techniques, leaving contractors little 
room to maneuver, than to follow Herzberg's theory in the construction industry. However, Olomolaiye and Price (1989) assert that Haseltine's reason are not sufficient for a wholesale adoptions of Herzberg's theory in the construction industry, as the "open shop" nature of workers in the United Kingdom make them to identify more with management goals and be motivated not only as Herzberg suggested.

In relating Maslow's theory to the construction industry, most of the conceptual applications lack empirical verification. For example, Schrader (1972) believes that American construction workers can meet their physiological need when employed, because they earn enough money to pay for them, thus confirming Maslow's ranking that these needs are least important. Haseltine (1976) agrees with Schrader's claims that most working people have satisfied their basic needs and are only motivated by higher needs. Self actualisation needs are the highest in the Maslow's hierarchy, though Schrader's descriptive work holds that they are pertinent, they are frequently faulted in construction industry, for example, some craftsmen who could have been promoted prefer to practice their craft without shouldering responsibilities of foremen.

Furthermore, the study conducted by Wilson (1979) on motivation of operatives sought to acquire knowledge of motivation in the construction industry using an empirical approach. Wilson found in the study that the greatest motivator were safety and belonging needs. Their findings were later tabulated against Maslow's hierarchy by Mckenzie and Harris (1984) to conclude that Maslow's theory explain motivation in construction only partially in the early stages of the hierarchy.

In the same vein, Maloney (1981) assessed Magregor's theories and concluded that the theories are fundamentally wrong in proposing a "best" way of motivating employees and rigidly categorising workers as $\mathrm{X}$ and Y. Instead Maloney suggested that since individuals differ, their behaviour should rather be conceived as a continum of the assumptions made in both theories.

\section{Conclusion and recommendation}

The paper notes that because human beings do not behave in a regimented or mechanistic way as equipments, optimising the coordinating service they provide to all other resources of production in construction depends on fuller understanding of their inherent peculiarities, with a view to devising better means of motivating them for optimum performance.

The study concludes that motivation techniques being used in the construction industry have their roots in the basic. Maslow's, Herzberg's and Magregor's theories, underlying such practices in the manufacturing and services industries. The motivation techniques used are broadly categorized as financial, semi financial, and non financial motivators. There is also ample evidence that the use of these motivators have led to noted additions to productivity of workers in the construction industry. However, in spite of their positive contributions, a wholesale adoption of these theories has not been possible because of the industries peculiarities.

Though, it is amply agreeable that in an effort to improve the situation in the construction industry the foundational motivation theories should be kept, it is suggested that, collation and summary of empirical based flaws in the application of these theories in the construction industry should be carried out. And a further test of the effects of these peculiarities on the effectiveness of these theories which have been effective elsewhere should be conducted. This may be the basis for evolving construction industry friendly theories.

\section{References}

[1]. Adams, J.S. (1965) 'Inequity in social Exchange in Advances in experimental social Psychology: L.N. Brewick (Ed.). 2, Academic Press, pp.267-300.

[2]. Aina, O.O. (2000) The Effect of Incentive Schemes on Construction Productivity in Nigeria. M.Sc. Thesis, Obafemi Awolowo University, Ile-Ife, Nigeria.

[3]. Berelson, B. and Steiner G.H. (1964) Human Behaviour: An Inventory of Scientific findings. New York. Harcourt Brace Javanorvich.

[4]. Borcherding, J.D. and Laufer, A. (1981) Financial Incentive to raise Productivity: Journal of Construction Division, American. Society of civil Engineers (ASCE) 107, 99 745-756.

[5]. Dunnette, M.O. (1973): Work and Non-work in the Year 2001. California Wordsworth Publishing Co.

[6]. Eze, N. (1995) Human Resource Management in Africa: Problems and solution. Lagos, Zomax press.

[7]. Halloran, J. (1978) Applied Human Relations Prentice - Hall, New Jersey.

[8]. Haseltine, C.S. (1976)“Motivation of Construction workers" Journal of Construction Division ASCE 102 pp. 497-509.

[9]. Herzberg. F. and Mauswer, B. (1959) The Motivation to Work John Wiley, New York.

[10]. Langford. D. et al (1995) Human Resources Management in Construction. Longman,Essex.

[11]. Locke, E.A. (1968) Towards a theory of task motivation and incentives.

[12]. Organisational Behaviour and Performance. 3, pp. 157-189.

[13]. McGregor, D.M. (1960)The Human Side of Enterprise McGraw Hill. New York.

[14]. Maloney, W.F. (1983) Productivity Improvement: The Influence of Labour. Journal of Engineering and Management ASCE. 109 (3) pp.311-334.

[15]. Mascon, M.H. et al (1985)___ Management: Individual and Organisational Effectiveness. Harper and Row, New York.

[16]. Maslow, A. (1943)A theory of human motivation, Psychology Review. 50 pp.370-396.

[17]. McCormic, E.J. and Daniel. I. (1985)Industrial and Organisational Psychology $8^{\text {th }}$ Edition, Allen and Union, Sydney.

[18]. New Combe, R. et al (1990) Construction Management: Organisation Systems. Vol. 1. Mitchel, London

[19]. Novaceck, J. and Lazarus, R.S. (1990)The structure of Personal Commitment. Journal of Personalty. 58(4) 693-715. 
[20]. Olomolaiye P.O. and Price. A.D.F. (1989) “A review of Construction Operative Motivation” Building and Environment Vol. 24. No. 3 pp. 279-287.

[21]. Porter, L.W. and Lawler. E.E. (1968)Managerial attitudes and Performance. Irwing Dorsey.

[22]. Pritchard, R.D. (1969)Equity Theory: a review and critique in Organisation behaviour and human Performance 4. pp. 176-211.

[23]. Robbins, S.P. (1991)Management: Concepts and Practices $3^{\text {rd }}$ Edition. Prentice Hall, New Jersey.

[24]. Shrader, C.R. (1972)Boosting Construction worker Productivity. Journal of Engineering ASCE, $42,61-63$.

[25]. Steers, R.M. and Porter, L.W. (Eds) (1983) Motivation and Work Behaviour. McGraw Hill. New York.

[26]. Vroom, V.H. (1964)Work and motivation. John Wiley, New York.

[27]. Wilson, D.J. (1979)Need importance and need satisfaction for construction Operatives. Unpublished M.Sc. Project Report. Loughborough University of Technology.

[28]. Yap, G.H (1992) Herzberg and the motivation of labour only subcontractors. Unpublished M.Sc. Thesis, University of Bath 